\title{
BMJ Open Does cigarette demand respond to price increases in Uganda? Price elasticity estimates using the Uganda National Panel Survey and Deaton's method
}

\author{
Grieve Chelwa, ${ }^{1}$ Corne van Walbeek ${ }^{2}$
}

To cite: Chelwa G, van Walbeek C. Does cigarette demand respond to price increases in Uganda? Price elasticity estimates using the Uganda National Panel Survey and Deaton's method. BMJ Open 2019;9:e026150. doi:10.1136/ bmjopen-2018-026150

- Prepublication history for this paper is available online. To view these files, please visit the journal online (http://dx.doi. org/10.1136/bmjopen-2018026150).

Received 18 September 2018 Revised 22 January 2019 Accepted 24 January 2019
A) Check for updates

(c) Author(s) (or their employer(s)) 2019. Re-use permitted under CC BY. Published by BMJ.

${ }^{1}$ Graduate School of Business, University of Cape Town, Cape Town, South Africa

${ }^{2}$ School of Economics, University of Cape Town, Cape Town, South Africa

Correspondence to

Dr Grieve Chelwa;

grievechelwa@gmail.com

\section{ABSTRACT}

Objective To provide the first published estimates of the price elasticity of demand for cigarettes in Uganda and thereby contribute to growing the evidence base of the likely impact of excise taxes on cigarette consumption and tax revenues in Sub-Saharan Africa.

Method We use a linear approximation of the Almost Ideal Demand System along with expenditure data from the Uganda National Panel Survey and exploit the fact that prices of cigarettes vary across geographical space in Uganda.

Results We find that cigarettes are price inelastic in Uganda with elasticity estimates ranging between -0.26 and -0.33 . That is, we expect that cigarette demand will decline by between $2.6 \%$ and $3.3 \%$ every time cigarette prices rise by $10 \%$. These elasticity estimates are in line with international evidence and are robust to outliers in the data.

Conclusion Our estimates of the price elasticity of demand for cigarettes suggest that the authorities in Uganda can reduce cigarette consumption and simultaneously increase tax revenues by increasing the excise taxes on cigarettes.

\section{INTRODUCTION}

Uganda's smoking prevalence estimates are relatively high by African standards. According to the World Health Organisation (WHO), estimates for adult smoking prevalence for males and females were $17 \%$ and 3\% respectively in 2016. ${ }^{1}$ Comparable estimates for Africa place adult male and female smoking prevalence at $17 \%$ and 2\%, respectively. Among Ugandan youths, smoking prevalence is even higher at $19 \%$ for males and $16 \%$ for females. ${ }^{2}$ Prevalence is relatively high in Uganda in comparison with other African countries because Uganda has, in the recent past, experienced relatively impressive economic growth with a modest increase in the real price of tobacco products. For example, Ho et $\mathrm{al}^{3}$ estimate that gross national income per capita increased by 107\% between 1999 and 2013. Over the same

\section{Strengths and limitations of this study}

- This paper aims at filling the evidence gap for the local impact of excise taxes on cigarette demand in an African setting with specific reference to Uganda.

- There is yet to be a published estimate of the price elasticity of demand for cigarettes in Uganda, a country where excise taxes are low.

- The paper uses the method pioneered by Angus Deaton that exploits the fact that prices of most commodities in developing countries vary across geographical space.

- A limitation is that the paper only estimates conditional price elasticities (for current cigarette smokers only) and not total price elasticities (conditional plus participation elasticities).

period, real cigarette prices only increased by $42 \%{ }^{3}$ Therefore, smoking prevalence and tobacco consumption in Uganda will increase in the coming years if these trends continue.

Increasing excise taxes on tobacco products is the single-most effective policy tool for reducing the demand for tobacco products. ${ }^{45}$ Unfortunately, excise taxes in Uganda are low and well below the WHO's recommended target. The percentage of the cigarette retail price that is due to the excise tax (known as the excise tax burden) was estimated at $40 \%$ in $2017 .^{2}$ WHO recommends an excise tax burden of at least $70 \%$ of the retail price. ${ }^{6}$ We know from several studies that cigarettes (and all other tobacco products) are generally price inelastic. Available estimates put the price elasticity of demand for cigarettes in the range of -0.20 to $-0.60 .{ }^{45}$ The implication of these estimates is that by increasing taxes on cigarettes, countries can decrease consumption and at the same time increase tax revenues.

To the best of our knowledge, there are no published estimates of the price elasticity of demand for cigarettes that focus 
specifically on Uganda. As a matter of fact, there are very few published estimates of the price elasticity of demand for cigarettes and tobacco products in Africa. The comprehensive survey of the literature on the price elasticity of demand for cigarettes by the International Agency for Research on Cancer was only able to list two sub-Sahara African countries (South Africa and Zimbabwe) as having published estimates of the price elasticity of demand. ${ }^{5}$ These studies found price elasticity estimates ranging between -0.16 and -1.52 . Using panel data techniques, Ho et $\mathrm{al}^{3}$ have recently provided estimates of the price elasticity of demand for cigarettes for the African continent using a sample of 36 countries. Their full-sample estimate of -0.50 is right within the range of international estimates. ${ }^{45}$ Much like the international literature, Ho et $\mathrm{al}^{3}$ show that there is heterogeneity in elasticity estimates by income category. Low-income African countries have, as a group, the highest elasticity estimates with high-income countries having the lowest estimates.

Even though we expect cigarettes to be price inelastic in most countries, policy-makers still demand local evidence before initiating policy changes. There is, therefore, a need to generate local evidence in Africa to support civil society's efforts in encouraging governments to increase the excise tax as part of a comprehensive strategy. Often generating local evidence is constrained by the unavailability of appropriate data. The method used in this paper uses expenditure data, widely available on the continent, to estimate elasticities. The fact that expenditure data are widely available on the African continent means that Deaton's method holds much promise for generating local evidence on the continent. A small literature has recently emerged that uses Deaton's method in estimating price elasticities of demand for cigarettes in low-income and middle-income countries (LMICs). ${ }^{7-11}$ This literature's price elasticity estimates $(-0.10$ to -0.60$)$ are in line with studies that use more traditional time series methods $(-0.20$ to -0.60$)$. This method is yet to be applied to an African country and Uganda provides us with a unique opportunity to demonstrate the efficacy of the method.

\section{METHOD}

This paper uses the method proposed by Deaton ${ }^{12}$ and extended in subsequent years ${ }^{13-15}$ to estimate price elasticities for cigarettes in Uganda. The method uses the fact that prices of most goods in LMICs are similar within narrowly defined clusters like villages but vary across clusters owing to the presence of significant transportation costs as goods move from one cluster to the next. The fact that price variation is largely induced by an external factor (transportation costs) allows one to estimate demand elasticities that are free from concerns of reverse causality or simultaneity bias. Deaton's method has an added layer of attraction for researchers working in Africa because it only uses household expenditure surveys which are available in abundance on the continent. Traditionally, the literature on tobacco demand has estimated price elasticities using aggregate time series data on cigarette consumption and prices. This partly explains why there are only a handful of countries on the continent with estimates of the price elasticity of demand: many African countries do not maintain time series data of a sufficient time length to allow for a proper estimate of elasticities. On the other hand, many African countries often conduct household expenditure surveys every so often for the purposes of constructing, among other things, Consumer Price Indices (CPIs).

Deaton's method proceeds in a series of steps. First, the researcher extracts unit values (a proxy for prices) from the survey data at the household level. This is done by dividing total expenditure on cigarettes by the quantity demanded of cigarettes or algebraically as

$$
v_{i c} \equiv \frac{c i g_{i c}}{q_{i c}}
$$

where $v_{i c}, c i g_{i c}$ and $q_{i c}$ are respectively the unit value, expenditure and quantity of cigarettes in household $i$ located in cluster $c$. Deaton uses unit values as opposed to actual prices because household expenditure surveys rarely collect information on the prices faced by individual households. However, unit values are not the same thing as prices. For one thing, unit values hide a great degree of quality heterogeneity whereas the classic treatment of demand concerns itself with homogeneous goods. With quality heterogeneity, households may respond to a price increase by shifting to a lower 'quality' brand of cigarettes with a small decline in quantity. Deaton refers to this as 'quality shading'. With quality shading, the price elasticity of demand will be overestimated. Second, unit values are not the same as prices because of measurement error. Households are unlikely to correctly recall the amount of money spent on cigarettes and/or the quantity consumed. In some cases, the survey enumerator might incorrectly capture this information. In such a case, (1) would result in a wrong price even if cigarettes were a homogeneous product (ie, cigarettes were not susceptible to quality shading). The presence of measurement error will bias the estimate of the price elasticity of demand. Fortunately, Deaton has proposed formulae that allow the researcher to correct their final elasticity estimates of quality shading and measurement error (see below).

The second step in Deaton's method involves checking whether the main identifying assumption, that prices (unit values) vary spatially, holds for the unit values obtained above. This is done by using analysis of variance (ANOVA) to divide the total variation in unit values into 'within cluster variation' and 'between cluster variation'. A large F statistic for the ANOVA exercise leads to the conclusion that unit values vary across space. In a third step, one estimates within cluster regressions of the form:

$$
\begin{gathered}
\ln v_{i c}=\lambda+\beta \ln x_{i c}+\gamma \mathbf{Z}_{i c}+\psi \ln \pi_{c}+e_{i c} \\
w_{i c}=\alpha+\varepsilon \ln x_{i c}+\delta Z_{i c}+\theta \ln \pi_{c}+\left(F E_{c}+u_{i c}\right)
\end{gathered}
$$


$w_{i c}$ represents the share of cigarette expenditure in total household expenditure for household $i$ in cluster $c$ and $l n v_{i c}$ is the log of the unit value, derived according to identity (1) for household $i$ in cluster $\ln x_{i c}$ is the $\log$ of total household expenditure over the relevant reference period. $Z_{i c}$ is a vector of household specific characteristics including household size, household gender composition, gender of the household head, proportion of adults in the household and years of schooling of the household head. Other variables in $\boldsymbol{Z}_{i c}$ are the age of the household head and a dummy variable for whether the household head is formally employed or not. $F E_{c}$ is a cluster fixed effect. $u_{i c}$ and $e_{i c}$ are the standard regression error terms. $\ln \pi_{c}$ are the unobserved prices and consequently, equations (2) and (3) are estimated without them. The coefficients on the price terms can, however, be recovered (see below).

Equation (2), referred to as the 'unit value' equation, allows us to check for the presence of quality effects in the unit value data. A positive and statistically significant relationship between household expenditure and unit values, after accounting for household characteristics, would suggest the presence of quality effects. That is, richer households report higher unit values primarily because they are buying cigarettes of a higher quality. Knowing the pattern of the quality effects (ie, the magnitude of $\beta$ ), allows us to correct our final price elasticity estimates for quality shading. It is also important to note that some portion of the variation in unit values comes from these choices in quality that households are making. This variation is also exploited below in estimating our elasticities. Equation (3), on the other hand, is a standard demand equation where the cigarette share is expressed as a function of household income (proxied by household expenditure), household characteristics and prices. The cluster fixed effects allow us to control for cluster-level tastes and preferences. Similar tastes and preferences are to be expected for narrowly constructed clusters such as villages. Equations (2) and (3) also contain useful information about measurement error at the household level. The magnitude of the errors are captured by $e_{i c}$ and $u_{i c}$, the regression error terms. The relationship between the two errors (as captured by, say, the covariance) is useful in correcting the final price elasticity estimates for measurement error (see more below).

The fourth step involves stripping the household-level demand and unit values of the effects of household expenditure and household characteristics and then averaging across clusters. This step requires the following equations:

$$
\begin{gathered}
\hat{y_{c}^{1}}=\frac{1}{n_{c}} \sum_{i=1}^{n_{c}}\left(\ln v_{i c}-\hat{\beta} \ln x_{i c}-\hat{\gamma} \boldsymbol{Z}_{i c}\right) \\
\hat{y_{c}^{2}}=\frac{1}{n_{c}} \sum_{i=1}^{n_{c}}\left(w_{i c}-\hat{\varepsilon} \ln x_{i c}-\hat{\boldsymbol{\delta}} \boldsymbol{Z}_{i c}\right)
\end{gathered}
$$

where $n_{c}$ is the number of households in cluster $c$. $\hat{y}_{c}^{1}$ and $\hat{y}_{c}^{2}$ are the estimates of, respectively, cluster average unit value and cluster average demand after removing the effects of household expenditure and household characteristics (notice that $\hat{y}_{c}^{1}$ and $\hat{y}_{c}^{2}$ do not have the $i$ subscript because they represent cluster averages). Recall that our identifying assumption is that prices vary at the cluster level (ie, between clusters and not within clusters). Given this identifying assumption, price elasticities of demand can only be obtained by seeing how cluster-level demand responds to changes in cluster-level prices. This leads to the fifth step which involves regressing cluster-level demand, $\hat{y}_{c}^{2}$, on cluster-level unit values, $\hat{y}_{c}^{1}$. The coefficient on in such a regression can alternatively be obtained by dividing the covariance between $\hat{y}_{c}^{2}$ and $\hat{y}_{c}^{1}$ by the variance of $y_{c}^{1}$. That is $\hat{\phi}$, the estimate of the coefficient on $y_{c}^{1}$, is obtained by

$$
\hat{\phi}=\frac{\operatorname{Cov}\left(\hat{y_{c}^{2}}, \hat{y_{c}^{\hat{1}}}\right)-\frac{\sigma \hat{1} 2}{n_{c}}}{\operatorname{Var}\left(\hat{y_{c}^{1}}\right)-\frac{\sigma^{\hat{1} 1}}{n_{c}^{+}}}
$$

where $n_{c}^{+}$is the number of households in a village reporting positive expenditures on tobacco and $n_{c}$ is the number of households in a village; $\sigma^{\hat{1} 2}$ is the estimate of the covariance of the errors in equations (2) and (3); $\sigma^{\hat{1} 1}$ is the variance of the errors in equation (2). These are included in equation (6) to adjust our estimates for measurement error.

The sixth and final step in Deaton's method applies quality correction formulas in obtaining the estimate of the price elasticity of demand, $\hat{\varepsilon_{P}}$, as follows:

$$
\hat{\varepsilon_{P}}=\left(\frac{\hat{\theta}}{\bar{w}}\right)-\hat{\psi}
$$

where $\bar{w}$ is the average share of total household expenditure dedicated to cigarettes in the sample. $\hat{\psi}$ and $\hat{\theta}$, the estimates of the coefficients on the unobserved price terms in equations (2) and (3), respectively, are recovered as follows:

$$
\begin{gathered}
\hat{\psi}=1-\frac{\hat{\beta}(\bar{w}-\hat{\theta})}{\hat{\varepsilon}+\bar{w}} \\
\hat{\theta}=\frac{\hat{\phi}}{1+(\bar{w}-\hat{\phi}) \hat{\zeta}} \\
\hat{\zeta}=\frac{\hat{\beta}}{\hat{\varepsilon}+\bar{w}(1-\hat{\beta})}
\end{gathered}
$$

$\hat{\beta}$ is the estimate of the coefficient on total household expenditure in equation (2), the within-cluster unit value equation, and $\hat{\varepsilon}$ is the estimate of the coefficient on total household expenditure in equation (3), the within-cluster demand equation. $\hat{\phi}$ is the estimate of the coefficient of a regression of cluster-level demand on cluster-level unit value (from equation 6).

Deaton also proposes the following formula for obtaining the estimate of the expenditure elasticity of demand, $\hat{\varepsilon}_{I}$ : 


$$
\hat{\varepsilon}_{I}=1+\left(\frac{\hat{\varepsilon}}{\bar{w}}\right)-\hat{\beta}
$$

\section{Data}

The data come from the 2005 and 2009 editions of Uganda's National Panel Survey (UNPS), a nationally representative survey. The UNPS is conducted by the Uganda Bureau of Statistics with technical assistance from the World Bank. Households that were surveyed in 2005 were revisited in 2009. Additional panel studies have been conducted since 2009. This paper does not use data from latter rounds because these surveys did not collect sufficiently detailed information on the quantities of cigarettes purchased by households. Specifically, information on whether the unit of purchase was a stick, packet or bundle was missing from the latter rounds of the survey. Deaton's method requires that the units for the quantity variable be the same. Further, we do not exploit the panel characteristics of the paper but instead treat 2005 and 2009 as separate cross-sections.

The UNPS collects an exhaustive list of information on the socioeconomic characteristics of households. This includes information on household expenditure patterns, household composition patterns and the occupational and educational status of household members. In the household expenditure module of the survey, which is this paper's primary interest, households are required to recall expenditure on various goods and services. The recall period ranges from 7 days for cigarettes to 1 year for household expenditures on education, health and clothing to name a few. We convert all expenditures into weekly expenditures.

The expenditure module collects information on the quantity and total amount paid for cigarettes over the last 7 days. The quantities are recorded either as sticks or packets. We convert sticks into packets by dividing them by 20 which is the number of cigarettes in a pack in Uganda. Another unfortunate aspect of the UNPS is that it does not distinguish between zero expenditures and expenditure information that is simply missing. In other words, a household's information on cigarette expenditure is left out of the survey if (1) the household reported zero expenditure on cigarettes in the previous week or (2) the household was never asked this question or (3) the respondent did not know the answer to the question. Notice that case (1) coincides with a scenario where the household consumes cigarettes but did not do so in the previous week because, say, the price was high (ie, a corner solution). It also coincides with a scenario where the household does not consume any cigarettes at all. On the other hand, cases (2) and (3) are scenarios where information is simply missing. Because the survey is not explicit about distinguishing zero expenditures from missing expenditures, we choose to only use households that reported positive cigarette expenditures in estimating the price elasticity of demand. In other words, we estimate conditional price elasticities of demand. To
Table 1 Summary statistics from the Uganda National Panel Survey

\begin{tabular}{|c|c|c|}
\hline Variable & 2005 & 2009 \\
\hline $\begin{array}{l}\text { Percentage of households with } \\
\text { positive cigarette expenditure }\end{array}$ & $9 \%$ & $7 \%$ \\
\hline $\begin{array}{l}\text { Average cigarette share in total } \\
\text { household expenditure }\end{array}$ & $8.86 \%$ & $7.67 \%$ \\
\hline Real average unit value per pack & 1952.11 & 1056.26 \\
\hline $\begin{array}{l}\text { Average unit value per pack (US\$ } \\
\text { equivalent) }\end{array}$ & 0.83 & 0.45 \\
\hline $\begin{array}{l}\text { Average weekly quantity of } \\
\text { cigarettes (in packs) }\end{array}$ & 1.45 & 1.55 \\
\hline $\begin{array}{l}\text { Ave. real household expenditure } \\
\text { (last } 7 \text { days in Ugandan shillings) }\end{array}$ & 34598. & 32784. \\
\hline $\begin{array}{l}\text { Ave. household expenditure (last } \\
7 \text { days US } \$ \text { equivalent) }\end{array}$ & 14.72 & 13.95 \\
\hline Average household size & 5.58 & 6.33 \\
\hline $\begin{array}{l}\text { Average age of household head in } \\
\text { years }\end{array}$ & 41.13 & 43.73 \\
\hline Average proportion of male heads & $86.81 \%$ & $90.17 \%$ \\
\hline Average proportion of adults & $54.58 \%$ & $46.88 \%$ \\
\hline $\begin{array}{l}\text { Average proportion of males in } \\
\text { household }\end{array}$ & $53.27 \%$ & $52.00 \%$ \\
\hline $\begin{array}{l}\text { Average years of schooling of } \\
\text { household head }\end{array}$ & 6.55 & 5.81 \\
\hline $\begin{array}{l}\text { Average proportion of heads with } \\
\text { some employment }\end{array}$ & $89.74 \%$ & $84.43 \%$ \\
\hline Total number of clusters & 322 & 318 \\
\hline Total number of effective clusters & 178 & 121 \\
\hline Total number of households & 274 & 173 \\
\hline $\begin{array}{l}\text { Average number of households per } \\
\text { cluster }\end{array}$ & 1.54 & 1.43 \\
\hline
\end{tabular}

Summary statistics for the relevant variables from the 2005 and 2009 Uganda National Panel Survey (UNPS). Adults are those household members who are 18 years or older.

allow for comparisons across years, we express all unit values and total expenditures in terms of 2010 prices using Uganda's CPI. ${ }^{16}$

Table 1 reports summary statistics for the relevant variables from the data.

Eight per cent of the sample of households from 2005 reported positive expenditures on cigarettes in the last 7 days. For 2009, this number was $7 \%$. The share of the weekly budget allocated to cigarette expenditure was, on average, $8.86 \%$ in 2005 and $7.67 \%$ in 2009. Although Uganda's cigarette expenditure share is relatively high, it falls within the range identified by John ${ }^{17}$ particularly for LMICs. The reported average unit value per pack in 2010 Ugandan shillings was 1952 (83 US cents) in 2005 and 1056 (45 US cents) in $2009 .{ }^{18}$ To the extent that unit values are a good proxy of actual prices, then the foregoing would suggest that cigarettes became cheaper, in real terms, by about $46 \%$ over the four year period in 
Table 2 Testing the spatial variation hypothesis

\begin{tabular}{|c|c|c|c|c|c|c|c|}
\hline \multicolumn{4}{|c|}{2005 sample } & \multicolumn{4}{|c|}{2009 sample } \\
\hline F statistic & $P$ value & $\mathbf{R}^{2}$ & $\mathbf{n}$ & F statistic & P value & $\mathbf{R}^{2}$ & $\mathbf{n}$ \\
\hline 1.29 & 0.08 & 0.70 & 274 & 1.12 & 0.33 & 0.72 & 173 \\
\hline
\end{tabular}

The F statistic and the $\mathrm{p}$ value are associated with the null hypothesis of no spatial variation in unit values. The hypothesis is rejected in the 2005 sample but not in the 2009 sample. The $R^{2}$ measures the proportion of variation in prices taking place between clusters. $n$ is the total number of households.

question. The average weekly household expenditure expressed in 2010 Uganda shillings was 34598 (US\$15) in 2005 and declined slightly by $5 \%$ to 32784 (US\$14) in 2009. The rest of the summary statistics in Table 1 mainly pertain to the $\boldsymbol{Z}$ vector of control variables used in the regressions (see equations 2 and 3 above).

\section{Patients and public involvement}

Patients and the public were not involved in this study.

\section{RESULTS}

The main identifying assumption behind Deaton's method is that prices vary across geographical space. The validity of this assumption can be tested using ANOVA techniques. We report the results of the ANOVA exercise in table 2. According to the results of the ANOVA procedure, most of the variation in unit values takes place between clusters. The $\mathrm{R}^{2}$, which measures the proportion of total variation in unit values between clusters, is at least $70 \%$. The F statistics associated with a null hypothesis of no spatial variation is large for the 2005 sample and not for the 2009 sample. Even with the 2009 sample, the $\mathrm{R}^{2}$ is $72 \%$. In large part, the assumption of spatially varying prices is confirmed by the data. John ${ }^{78}$ also finds that cluster effects explain at least $70 \%$ of the variation in unit values in India.

Tables 3 and 4 show the results of running the unit value and budget share regressions (equations 2 and 3) on the two samples. The results for the unit value regression are reported in table 3 . The results show that quality effects are present in the data: households with higher household expenditure tend to report higher unit values controlling for other household characteristics. Reported unit values rise by between $1 \%$ and $2 \%$ for every $10 \%$ increase in household expenditure. These so-called expenditure elasticities of quality compare favourably with those estimated for cigarettes by John, ${ }^{78}$ Eozenou and Fishburn, ${ }^{9}$ Guindon et al., ${ }^{10}$ and Chen and Xing. ${ }^{11}$

Table 4 reports the results of running the budget share regression (equation 3) on household expenditure alongside other household characteristics and cluster fixed-effects. In table 4, there is a negative and statistically significant relationship between household expenditure and the share of the household budget allocated to cigarettes. The cigarette budget share tends to fall as household expenditure rises. The cluster fixed effects, whose results are not presented in table 4 for purposes of space, are all jointly statistically significant at the $1 \%$ level for the 2005 and at the $10 \%$ level for the 2009 sample. This means that unobserved but fixed factors at the cluster level (tastes, preferences, etc) matter for cigarette demand.

\begin{tabular}{|c|c|c|}
\hline & (2005) & (2009) \\
\hline Variables & Inv & Inv \\
\hline \multirow[t]{2}{*}{$\ln x$} & $0.234^{\star \star \star}$ & $0.115^{\star \star}$ \\
\hline & $(0.051)$ & $(0.048)$ \\
\hline \multirow[t]{2}{*}{ Size } & -0.042 & -0.010 \\
\hline & $(0.124)$ & $(0.119)$ \\
\hline \multirow[t]{2}{*}{ Adults } & -0.203 & 0.159 \\
\hline & $(0.295)$ & $(0.300)$ \\
\hline \multirow[t]{2}{*}{ Males } & 0.261 & 0.131 \\
\hline & $(0.216)$ & $(0.223)$ \\
\hline \multirow[t]{2}{*}{ Education } & $-0.143^{\star}$ & 0.108 \\
\hline & $(0.080)$ & $(0.074)$ \\
\hline \multirow[t]{2}{*}{ Age } & -0.015 & $-0.409^{\star \star}$ \\
\hline & $(0.153)$ & $(0.166)$ \\
\hline \multirow[t]{2}{*}{ Gender } & 0.217 & 0.218 \\
\hline & $(0.163)$ & $(0.183)$ \\
\hline \multirow[t]{2}{*}{ Work } & -0.144 & 0.101 \\
\hline & $(0.141)$ & $(0.118)$ \\
\hline \multicolumn{3}{|l|}{ Year } \\
\hline \multirow[t]{2}{*}{ Constant } & $4.957^{\star \star \star}$ & $6.602^{\star \star \star}$ \\
\hline & (0.692) & $(0.739)$ \\
\hline No of households & 233 & 147 \\
\hline $\mathrm{R}^{2}$ & 0.115 & 0.126 \\
\hline
\end{tabular}

Results of the regression of the log of unit value (Inv) on the log of household expenditure (Inx) and other household characteristics (see equation 2). Household size (Size), education of household head (Education) and age of household head (Age) are in natural logarithms. Adults refers to the proportion of adults in a household and adults are defined as aged 18 years or older. Males is the proportion of males in a household. Gender is a dummy variable which takes on the value of 1 if the household head is male and zero if they are female. Work is a dummy variable which takes on the value of 1 if the household head is employed and zero otherwise.

SEs are in parentheses.

${ }^{*} \mathrm{P}<0.1,{ }^{\star \star} \mathrm{P}<0.05,{ }^{* * *} \mathrm{P}<0.01$. 


\begin{tabular}{|c|c|c|}
\hline & (2005) & (2009) \\
\hline Variables & $\mathbf{w}$ & $\mathbf{W}$ \\
\hline \multirow[t]{2}{*}{$\ln x$} & $-0.056^{\star * *}$ & $-0.065^{\star \star \star}$ \\
\hline & $(0.017)$ & $(0.023)$ \\
\hline \multirow[t]{2}{*}{ Size } & 0.002 & 0.039 \\
\hline & $(0.031)$ & $(0.043)$ \\
\hline \multirow[t]{2}{*}{ Adults } & 0.008 & 0.092 \\
\hline & $(0.072)$ & $(0.103)$ \\
\hline \multirow[t]{2}{*}{ Males } & 0.013 & 0.010 \\
\hline & $(0.059)$ & $(0.068)$ \\
\hline \multirow[t]{2}{*}{ Education } & -0.001 & -0.012 \\
\hline & $(0.020)$ & $(0.025)$ \\
\hline \multirow[t]{2}{*}{ Age } & 0.028 & -0.077 \\
\hline & $(0.044)$ & $(0.072)$ \\
\hline \multirow[t]{2}{*}{ Gender } & -0.038 & $-0.108^{\star}$ \\
\hline & $(0.037)$ & $(0.056)$ \\
\hline \multirow[t]{2}{*}{ Work } & 0.037 & 0.058 \\
\hline & $(0.037)$ & $(0.039)$ \\
\hline \multicolumn{3}{|l|}{ Year } \\
\hline \multirow[t]{2}{*}{ Constant } & $0.533^{\star \star \star}$ & $0.963^{\star \star \star}$ \\
\hline & (0.193) & $(0.292)$ \\
\hline No. of households & 233 & 147 \\
\hline $\mathrm{R}^{2}$ & 0.866 & 0.909 \\
\hline
\end{tabular}

Results of the regression of the cigarette budget share (w) on the log of household expenditure $(\ln x)$ and other household characteristics (see equation 3). Household size (Size), education of household head (Education) and age of household head (Age) are in natural logarithms. Adults refers to the proportion of adults in a household and adults are defined as aged 18 years or older. Males is the proportion of males in a household. Gender is a dummy variable which takes on the value of 1 if the household head is male and zero if they are female. Work is a dummy variable which takes on the value of 1 if the household head is employed and zero otherwise. SEs are in parentheses. ${ }^{*} P<0.1$, ${ }^{* *} P<0.05$, ${ }^{* * *} \mathrm{P}<0.01$. Cluster fixed effects are suppressed for space reasons but are jointly statistically significant at the $1 \%$ level for the 2005 sample and at $10 \%$ for the 2009 sample.

Table 5 Estimates of the price elasticity of demand for cigarettes in Uganda

\begin{tabular}{lll} 
& (2005) & (2009) \\
\hline$\hat{\varepsilon_{P}}$ & $-0.326^{\text {** }}$ & $-0.258^{\text {** }}$ \\
& {$[0.021]$} & {$[0.011]$} \\
& $(-0.368$ to -0.284$)$ & $(-0.280$ to -0.235$)$ \\
No of households & 233 & 147 \\
No of clusters & 184 & 130 \\
\hline
\end{tabular}

Estimates of the price elasticity of demand for cigarettes in Uganda for the 2005 and 2009 samples. Bootstrapped SEs are in square brackets. $95 \% \mathrm{Cl}$ are in parentheses.

${ }^{\star} \mathrm{P}<0.1,{ }^{* \star} \mathrm{P}<0.05,{ }^{* \star} \mathrm{P}<0.01$.
Table 6 Estimates of expenditure elasticities of demand for cigarettes in Uganda

\begin{tabular}{lll}
\hline & (2005) & (2009) \\
\hline$\hat{\varepsilon}_{I}$ & $0.132[0.338]$ & $0.043[0.539]$ \\
No. of households & 233 & $(-0.531$ to 0.796) \\
\hline
\end{tabular}

Estimates of the expenditure elasticity of demand for cigarettes in Uganda for the 2005 and 2009 samples. Bootstrapped SEs are in square brackets. $95 \% \mathrm{Cls}$ are in parentheses. Since the expenditure elasticity of demand is estimated at the household level (see equation 11), we only report the number of households.

Table 5 presents our estimates of the price elasticity of demand for cigarettes in Uganda. The estimates are obtained using the information in tables 3 and 4 alongside the formulae in equations 4 to 10 above. SEs (in parentheses) are obtained by the method of the Bootstrap.

The estimates in table 5 show that cigarettes are price inelastic in Uganda. The estimates for the price elasticity of demand for the two samples are all statistically significant at the $1 \%$ level. For 2005 , the price elasticity is estimated at -0.33 while for the 2009 sample the estimate is at -0.26 . Taken together, these results imply that the demand for cigarettes in Uganda is expected to decline by about $3 \%$ for every $10 \%$ rise in prices. These results fall within the range of estimates for studies that use Deaton's method ( -0.10 to -0.60$)$ and studies using aggregate time series data $(-0.20$ to -0.60$)$.

Table 6 presents estimates of the expenditure elasticity of demand using equation (11) and coefficient estimates from tables 3 and 4 . The estimates in table 6 are imprecisely estimated and are, therefore, statistically insignificant.

\section{Robustness}

The estimates of the price elasticity of demand for cigarettes presented above are likely to be influenced by extreme unit values given that the sample sizes are relatively small. To check the robustness of our estimates, we follow Guindon et al. ${ }^{10}$ and exclude unit values that are greater than 2.5 SD and five SD from their respective means. (Given the similarity of the results in table 5 and the better performance of the 2005 sample in the ANOVA exercise, we only perform the robustness test on the 2005 sample).

Table 7 contains the estimates of the price elasticity of demand for cigarettes for the robustness tests. We have also included in table 7, estimates for the 2005 sample taken from table 5. The second column (column 2) excludes unit values that deviate by more than five SD from the mean while the third column (column 3), being more stringent, excludes unit values that deviate by more than 2.5 SD from the mean. The price elasticity estimates in columns 2 and 3 are statistically significant at the $1 \%$ level and 5\% level respectively and are similar to the estimate from the 2005 sample taken from table 5 . 
Table 7 Estimates of price elasticities of demand for cigarettes in Uganda (robustness check)

(2005 Full sample)

\begin{tabular}{llll}
\hline$\hat{\varepsilon_{P}}$ & $-0.326^{\star \star \star}[0.021]$ & $-0.351^{\star \star \star}[0.054]$ & $-0.271^{\text {**}}[0.120]$ \\
& $(-0.368$ to -0.284$)$ & $(-0.458$ to -0.246$)$ & $(-0.526$ to -0.017$)$ \\
No of households & 233 & 231 & 227 \\
No of clusters & 184 & 176 & 175 \\
\hline
\end{tabular}

Estimates of the price elasticity of demand for cigarettes in Uganda for the 2005 sample and for the 2005 sample with extreme unit values excluded. Column 1 (2005 sample) includes all unit values. In column 2, all unit values that are equal to or greater than five SD from the mean are excluded. In column 3, all unit values that are equal to or greater than 2.5 SD from the mean are excluded. Bootstrapped SEs are in square brackets. $95 \%$ confidence intervals are in parentheses.

${ }^{*} \mathrm{P}<0.1,{ }^{* *} \mathrm{P}<0.05,{ }^{* *} \mathrm{P}<0.01$.

\section{DISCUSSION}

This paper had two objectives in mind. First, to provide the first published estimates of the price elasticity of demand for cigarettes in Uganda, a country where prevalence and consumption are expected to increase in the future. The experience in other African countries, particularly South Africa, ${ }^{19}$ shows that consistently increasing excise taxes can play a significant role in reducing consumption. The evidence generated in this paper will be useful for policy-makers and civil society actors involved in tobacco control efforts in Uganda. The second aim for the paper was to demonstrate the efficacy of using Deaton's method in an African setting where the unavailability of appropriate data has in the past prevented the estimation of price elasticities. Deaton's method relies on expenditure data which is widely available across the African continent. This, alongside with the fact that our estimates for Uganda are in line with international evidence ${ }^{3-5}$ and in line with studies using Deaton's method, ${ }^{7-11}$ will hopefully encourage other researchers working on the continent to consider using this method for generating local evidence.

Our study focused on cigarettes because the first two rounds of the UNPS did not collect detailed enough information on other tobacco products to allow for the estimation of their elasticities using Deaton's method. Further, we were only able to estimate conditional elasticities because the UNPS does not distinguish between households reporting zero expenditure on cigarettes and those whose information is missing. Therefore, the total price response of cigarettes in Uganda is likely to be twice our estimated conditional elasticity of -0.30 given the empirical finding that the total elasticity is often double the magnitude of the conditional elasticity. ${ }^{5}$ This is similar to the finding in $\mathrm{Ho}$ et $\mathrm{al}^{3}$ where the (total) price elasticity of low-income African countries, in which Uganda is categorised, is estimated at -0.56 .

Given that our study only focused on cigarettes in Uganda, future research should aim at estimating price elasticities for other tobacco products and cross-price elasticities between cigarettes and other types of tobacco products. Cross price elasticities are important to know given the fact that levying taxes on cigarettes might not only affect cigarette demand, but could also increase the demand for other types of tobacco products. This, however, requires that the statistical authorities in Uganda consider collecting expenditure information on other types of tobacco products.

Contributors GC did the analysis and wrote up the paper together with CvW.

Funding This work was supported by funding from the African Capacity Building Foundation and ultimately from the Bill and Melinda Gates Foundation.

Competing interests None declared.

Patient consent for publication Not required.

Provenance and peer review Not commissioned; externally peer reviewed.

Data sharing statement All datasets are publicly available.

Open access This is an open access article distributed in accordance with the Creative Commons Attribution 4.0 Unported (CC BY 4.0) license, which permits others to copy, redistribute, remix, transform and build upon this work for any purpose, provided the original work is properly cited, a link to the licence is given, and indication of whether changes were made. See: https://creativecommons.org/ licenses/by/4.0/.

\section{REFERENCES}

1. World Health Organization. Global health observation data. 2018 Available at http://www.who.int/gho/tobacco/use/en/ (Accessed June 2018)

2. World Health Organization. Report on the global tobacco epidemic. Geneva: World Health Organization, 2017.

3. Ho LM, Schafferer C, Lee JM, et al. The effect of cigarette price increases on cigarette consumption, tax revenue, and smokingrelated death in Africa from 1999 to 2013. Int J Public Health 2017;62:899-909.

4. Chaloupka F, Warner KE. The economics of smoking. In: Newhouse J, Cutler D, eds. Handbook of Health Economics. Amsterdam: North Holland, 2000:1539-67.

5. International Agency for Research on Cancer. Handbook on the effectiveness of tax and price policies for tobacco control. Geneva: World Health Organization, 2011.

6. World Health Organization. Technical Manual on Tax Administration Geneva: World Health Organization, 2010. goods in India: Indira Gandhi Institute of Development Research, 2005. Working Paper Number WP-2005-003.

8. John RM. Price elasticity estimates for tobacco products in India. Health Policy Plan 2008;23:200-9.

9. Eozenou P, Fishburn B. Price elasticity estimates for cigarette demand in Vietnam: Development and Policies Research Center, 2009.

10. Guindon EG, Nandi A, Chaloupka FJ, Jha P. Socioeconomic differences in the impact of smoking tobacco and alcohol prices on smoking in India: National Bureau of Economics Research, 2011. Working Paper Number 17580.

11. Chen Y, Xing W. Quantity, quality, and regional price variation of cigarettes: Demand analysis based on a household survey in China. China Economic Review 2011;22:221-32.

12. Deaton A. Analysis of Household Surveys. Baltimore: Johns Hopkins Press, 1997.
7. John RM. Price elasticity estimates for tobacco and other addictive 
13. Deaton A. Quality, Quantity, and Spatial Variation of Price. American Economic Review 1988;78:418-30.

14. Deaton A. Household survey data and pricing policies in developing countries. World Bank Econ Rev 1989;3:183-210.

15. Deaton A. Price elasticities from Survey Data: extensions and Indonesian Results. Journal of Econometrics 1990;44:281-304.

16. We obtain the CPI from the World Development Indicators provided by the World Bank. Available here http://data.worldbank.org/datacatalog/world-development-indicators.
17. John RM. Crowding out effect of tobacco expenditure and its implications on household resource allocation in India. Soc Sci Med 2008;66:1356-67.

18. We convert 2010 Uganda shillings into US dollars by using the 2010 end of year exchange rate between the shilling and the dollar. www. oanda.com

19. Chelwa G, van Walbeek C, Blecher E. Evaluating South Africa's tobacco control policy using a synthetic control method. Tob Control 2016;26:509-17. 